\title{
Bacteriological Profile and Antibiotic Sensitivity Pattern of Neonatal Sepsis in Central Paediatric Referral Hospital in Nepal
}

\section{Susan Bhattarai ${ }^{1}$, Ram Hari Chapagain ${ }^{1}$, Deepak Mishra ${ }^{1}$, Anil Kumar Shrestha ${ }^{1}$ and Sushan Man Shrestha ${ }^{2}$}

${ }^{1}$ Department of Paediatrics, Kanti Children's Hospital, Maharajgunj, Kathmandu, Nepal

${ }^{2}$ Department of Community Medicine, Institute of Medicine, Maharajgunj, Kathmandu, Nepal

\section{Address for Correspondence: \\ Susan Bhattarai \\ Department of Paediatrics, \\ Kanti Children's Hospital, \\ Maharajgunj, Kathmandu, Nepal \\ Email: drsushan@gmail.com}

DOI: $10.3126 /$ jnps.v39i1.21070

Submitted on:2018-09-12

Accepted on: 2020-03-24

Acknowledgements: We would like to thank neonatal intermediate care unit, NICU, Microbiology department and Record Section of our Hospital.

Funding: Nil

Conflict of Interest: None declared

Permission form IRB: Yes

To cite this article: Bhattarai $\mathrm{S}$, Chapagain RH, Mishra D, Shrestha AK, Shrestha SM. Bacteriological profile and antibiotic sensitivity pattern of neonatal sepsis in central paediatric referral hospital in Nepal. J Nepal Paediatr Soc. 2019;39(1):1-5.

\section{ABSTRACT}

Introduction: Neonatal sepsis is the most common cause of neonatal morbidity and mortality. The causative organisms of neonatal sepsis are changing and so do their antibiotic sensitivity pattern. So it is important to regularly monitor the change in bacteriological profile and their antimicrobial sensitivity pattern to help update the treatment guidelines of neonates. This study aimed to study the microbiological patterns of neonatal sepsis and their antibiotic susceptibility pattern in a tertiary care centre in Kathmandu.

Methods: A prospective study was carried out among cases of neonatal sepsis admitted in Neonatal Intermediate Care Unit (NIMCU) of a tertiary care referral hospital from August 2015 to August 2016. Prospective data were collected with pretested and standardised proforma and analysed using SPSS version 20 .

Results: Out of 311 neonates admitted over a period of one year with diagnosis of neonatal sepsis, male:female ratio was 2.1:1. Among them $234(75.2 \%)$ cases were of LONS and $77(24.8 \%)$ were of EONS. Blood culture was positive in 47 neonates $(15.1 \%)$. The organisms isolated included staphylococcus aureus $(34.0 \%)$, klebsiella (32\%), CONS (24\%), escherechia coli (6\%) and enterobacter (4\%). In LOS, gram positive organisms staphylococcus and CONS were the commonest ones $(61.4 \%)$. In EOS, gram negative organism klebsiella $(65 \%)$ was more common. Most of staph aureus were susceptible to penicillins, amikacin and cefotaxime. Klebsiella was found to be resistant to penicillins, amikacin and cefotaxime.

Conclusion: There is possible increasing incidence of gram positive septicemia in LONS and increasing emergence of resistance of kleibsella to the common antibiotics ampicillin, amikacin and cefotaxime.

Key words: antibiotic susceptibility; neonatal sepsis; Nepal

(CC) This work is licensed under creative common attribution 3.0 license




\section{INTRODUCTION}

Neonatal sepsis is one of the major causes of morbidity and mortality among the newborns in the developing world. ${ }^{1}$ Neonatal infection currently causes about 1.6 million deaths per year in developing countries. It is estimated that $26 \%$ of the newborns who die do so as a result of infections that occur around birth. ${ }^{2}$

Early onset sepsis (EOS) refers to infections during the first 72 hours of life that is usually related to intrapartum transmission from mothers; whereas late onset sepsis (LOS) refers to postnatal acquisition of infections after the first three days of life. $^{3}$

Pathogens encountered in neonatal sepsis vary worldwide; reports from developing countries more commonly show Gram negative organisms ${ }^{4,5}$ although gram positive organisms have been also reported. These organisms have developed multidrug resistance over the last two decades. ${ }^{6}$ The reasons for this resistance are indiscriminate and irrational use of antibiotics, over the counter sale of antibiotics and ineffective infection control in maternity centres. ${ }^{7}$ This has currently lead to frequent use of second and third line antibiotics frequently in our institute.

The local epidemiological pattern of sepsis can be variable and this pattern can change with time. ${ }^{8}$ Timely microbiological surveillance and assessment of antimicrobial resistance is a key component in decreasing the rate of neonatal sepsis and the associated mortality. ${ }^{9}$ Thus regular monitoring and updates on the causes of neonatal sepsis and the antimicrobial sensitivity pattern is important for effective treatment and prevention of neonatal sepsis.

Therefore, in this current study, investigators aimed to describe the microbiological patterns and the antibiotic susceptibility pattern of the organisms isolated in blood culture in cases of neonatal sepsis in a tertiary care centre in Kathmandu.

\section{METHODS}

This is a prospective study done in tertiary care referral centre in Kathmandu, Nepal from August 2015 to August 2016 with pre approval from
Ethical Committee of the hospital. All the cases of neonatal sepsis admitted in the hospital were included in the study. Infants were classified into two groups according to the timing of sepsis diagnosis: EOS diagnosed $\leq 72$ hours of life and LOS diagnosed $>72$ hours of life. Demographic, clinical, and laboratory data were retrieved for all included infants. Blood culture reports and antibiotic sensitivity were studied. Data were collected and analysed using SPSS 20.

\section{RESULTS}

Total of 311 neonates were admitted in the hospital over a period of one year with the diagnosis of neonatal sepsis (NNS). There were 211 male neonates $(67.8 \%)$ and 100 female neonates (32.2\%) with male:female Ratio of 2.1:1. Among them 234 (75.2\%) cases were of LOS and 77 (24.8\%) were of EOS. Most of the cases of NNS were found in term infants $(92.6 \%)$ and in appropriate for gestational age group $(77.2 \%)$.

Out of 311 neonates, blood culture was positive in 47 neonates (15.1\%). In EOS, eight (10.3\%) neonates had organism isolated in blood culture whereas in LOS, 39 (16.6\%) had culture positivity. The organisms isolated included staphylococcus aureus in 16 cases, klebsiella in 15 cases, CONS in 11 cases, Escherichia coli in three and enterobacter in two cases.

In LOS, gram positive organisms, staphylococcus and CONS were isolated in $61.4 \%$ cases. In EOS, gram negative organism Klebsiella (65\%) was more common followed by staph aureus (35\%).

\section{DISCUSSION}

Neonatal sepsis is the leading cause of neonatal death worldwide. Neonatal mortality of Nepal is

Table 1. Bacterial isolates in blood culture

\begin{tabular}{|l|r|r|}
\hline Organism & Number & \multicolumn{2}{c|}{ Percentage } \\
\hline Staph. aureus & 16 & $34.03 \%$ \\
\hline Kleibsella & 15 & $31.9 \%$ \\
\hline CONS & 11 & $23.4 \%$ \\
\hline E. Coli & 3 & $6.3 \%$ \\
\hline Enterobacter & 2 & $4.26 \%$ \\
\hline
\end{tabular}


Table 2. Bacterial isolates in EOS and LOS

\begin{tabular}{l|rr|r|r|r|r|r} 
& \multicolumn{2}{c}{ Organism } & \multicolumn{2}{c}{ Total } \\
\hline & \multicolumn{3}{c}{ Gram positive } & \multicolumn{2}{c}{ Gram negative } \\
\cline { 2 - 9 } & CONS & \multicolumn{2}{c}{ Staphylococcus } & Klebseella & E.coli & Enterobacter & \\
\hline EOS & 0 & 3 & 5 & 0 & 0 & 8 \\
\hline LOS & 11 & 13 & 10 & 3 & 2 & 39
\end{tabular}

21/1000 live births. Timely microbiological survey and assessment of antimicrobial resistance is a key component in decreasing the rate of neonatal sepsis and the associated mortality. ${ }^{9}$

Majority of the neonates in our study were males with male:female ratio of 2.1:1. This was similar to that found in studies done in various institutes in Nepal. ${ }^{2,10,11}$ This might be because of the cultural factor that male children are given preference over females. $75.2 \%$ cases were of LOS and $24.8 \%$ were of EOS. Findings are similar to the study done in Bosnia. ${ }^{9}$ Comparable findings were reported in other studies from Egypt and South Africa. ${ }^{12,13}$ This is however in contrast to study done by Thapa B et al. in Kathmandu University. ${ }^{14}$ Similarly high incidence of EOS were also found in Pakistan. ${ }^{15}$ This is most probably because our study centre does not have birthing facility. It is the only tertiary level paediatric referral centre in the country and all neonates in the hospital are referred from all over the country.

Similarly, majority of the neonates are full term and appropriate for gestational age. This is again in contrast to other studies conducted in Addis Ababa, Nepal, Mexico and Indonesia, where preterm neonates had significant association with neonatal sepsis. This disparity can again be due to the fact that our hospital lacks birthing facility and most of

Table 3. Sensitivity and resistant pattern of the organisms isolated in blood culture

\begin{tabular}{|c|c|c|c|c|c|c|c|c|c|c|}
\hline & \multicolumn{2}{|c|}{$\begin{array}{c}\text { CONS } \\
\mathbf{N}=11\end{array}$} & \multicolumn{2}{|c|}{$\begin{array}{l}\text { Staph aureus } \\
N=16\end{array}$} & \multicolumn{2}{|c|}{$\begin{array}{l}\text { Klebsiellam } \\
\qquad \mathrm{N}=15\end{array}$} & \multicolumn{2}{|c|}{$\begin{array}{c}\text { E. Coli } \\
\mathbf{N}=3\end{array}$} & \multicolumn{2}{|c|}{$\begin{array}{c}\text { Enterobacter } \\
\mathbf{N}=\mathbf{2}\end{array}$} \\
\hline & $\mathbf{S}$ & $\mathbf{R}$ & $\mathbf{S}$ & $\mathbf{R}$ & $\mathbf{S}$ & $\mathbf{R}$ & $\mathbf{S}$ & $\mathbf{R}$ & $\mathbf{S}$ & $\mathbf{R}$ \\
\hline Amoxycillin & 4 & - & 9 & - & - & 2 & - & - & - & - \\
\hline Cloxacillin & 8 & - & 8 & - & - & - & - & - & - & - \\
\hline Ampicillin & 2 & 1 & 4 & 1 & - & 9 & - & - & - & - \\
\hline Amikacin & 6 & - & 9 & 2 & 4 & 8 & 2 & & 1 & 1 \\
\hline Cefotaxime & 4 & 2 & 7 & - & - & 4 & - & 1 & - & 1 \\
\hline Ciprofloxacin & 10 & - & 6 & - & 6 & 1 & - & - & - & - \\
\hline Ofloxacin & - & 1 & 1 & - & 8 & - & - & 1 & - & - \\
\hline Ceftazidime & 3 & 1 & 2 & - & 8 & 3 & - & - & - & 1 \\
\hline Cefipime & 1 & 1 & 3 & 2 & 6 & 3 & - & - & - & 1 \\
\hline Imipenem & - & - & - & - & 6 & - & - & - & 1 & - \\
\hline Vancomycin & 1 & - & - & - & - & - & - & - & - & - \\
\hline Meropenem & - & - & - & - & - & 1 & - & - & 1 & - \\
\hline
\end{tabular}

$S=$ Sensitive, $R=$ Resistant 
the cases are being referred from other health facilities a few days after birth.

Among 311 neonates, blood culture was positive in 47 neonates $(15.1 \%)$. This is similar to that done by Shrestha S et al. (13.6\%). ${ }^{2}$ Different studies have shown differing results ranging as low as $6.1 \%$ as done by Shrestha NJ et al. to as high as $21 \%$ by Barbara Js et al, $46.6 \%$ by G Eyesus et al. and $56.6 \%$ by Jain NK et al. ${ }^{10,11,16,17}$ The variation on these values could be because of differences in the lab resource and facilities. Furthermore it is also influenced by the practice of using antibiotics prior to the hospital arrival.

Organisms were isolated more in LOS (16.6\%) than EOS (10.3\%) though there is no statistical significance. Overall, Staphylococcus aureus is the commonest organism isolated followed by Klebsiella, CONS, E. Coli and Enterobacter. Similar results were found in the study done in Nepal, Nigeria and Gondar where gram positive organisms predominated the isolates. ${ }^{8,16,18}$ This is in contrast to other studies where gm negative organisms were predominant in causing neonatal sepsis. ${ }^{11,17}$

The most noteworthy changes observed are the studies done in this same institute during various times. The study done by Shrestha NJ et al. in 2008-2009 demonstrated E. Coli as the most common organism followed by staph aureus. ${ }^{10} \mathrm{But}$ in study done in 2014-2015 by Chapagain RH et al. in the same institute showed Staph aureus as the main cause of NNS followed by CONS. This might reflect the changing pattern of the organisms of neonatal sepsis over time though conclusion cannot be made based on this few samples. It has been shown that horizontal transmission from mothers is probably the major source of Staphylococcus aureus to neonates. ${ }^{19}$ This observation may therefore suggest poor hygiene as a major contributing factor to the high incidence of NNS in developing countries. It is also possible that the nasal and/or vaginal carriage rate of Staphylococcus aureus might have increased in our environment, though there are no studies available to show this.

Many organisms isolated in the blood culture are found to be sensitive to the traditional antibiotics recommended by WHO for the treatment of NNS but few cases showed resistance as well. Majority of Staph aureus isolated were sensitive to penicillin (amoxicillin, cloxacillin, ampicillin), amikacin, cefotaxime, and ciprofloxacin but two cases were resistant to amikacin and one to ampicillin. Similar results were found in the study done by Shrestha $\mathrm{S}$ et al in Kathmandu University Hospital, where 92\% isolates of Staphylococcus aureus were sensitive to amikacin and cloxacillin. However high resistance of $27 \%$ and $40 \%$ of Staphylococcus aureus to amikacin and cloxacillin respectively was found in the study done by Thapa B et al. at Paropakar Maternity and Women's Hospital. ${ }^{14}$ Study done at BPKIHS also showed increased resistance to penicillins. ${ }^{20}$ Similarly CONS was found to be sensitive to cloxacillin, ciprofloxacin and amikacin whereas two were resistant to cefotaxime and one was found to be resistant to amikacin.

The most remarkable resistance was observed with Klebsiella. Many of the times, it showed resistance to ampicillin, amikacin and cefotaxime which are most often used for the treatment of neonatal sepsis in our hospital. They were found to be sensitive to ceftazidime, cefipime and imipenem. Similar resistance pattern of gram negative organisms were observed in the study done in Pakistan. ${ }^{15}$

\section{CONCLUSIONS}

Pathogens for neonatal sepsis can change over time, so do their sensitivity pattern. This study suggests that gram positive organisms are becoming more dominant cause of neonatal sepsis and gram negative organisms are becoming more resistant to the common drugs used for treatment of NNS. Every institute should regularly monitor the microbiological profile with their sensitivity pattern of NNS that helps update the neonatal sepsis guideline for effective management of NNS.

\section{REFERENCES}

1. Stoll JB. Infections of neonatal infants. In: Kliegman MR SF, Geme WJ, SchorFN,et al ed. Nelson textbook of Pediatrics. 20 ed. London: Elsevier.; 2015. 
2. Shrestha S, Shrestha NC, Dongol Singh S, Shrestha RP, Kayestha S, Shrestha M, et al. Bacterial isolates and its antibiotic susceptibility pattern in NICU. Kathmandu Univ Med J (KUMJ). 2013;11(41):66-70. DOI:10.3126/kumj.v11i1.11030.

3. Mohsen L, Ramy N, Saied D, Akmal D, Salama N, Abdel Haleim MM, et al. Emerging antimicrobial resistance in early and lateonset neonatal sepsis. Antimicrob Resist Infect Control.. 2017;6:63. DOI:10.1186/s13756-017-0225-9.

4. Tallur SS, Kasturi AV, Nadgir SD, Krishna BV. Clinico-bacteriological study of neonatal septicemia in Hubli. Indian J Pediatr. 2000;67(3):169-74. DOI:10.1007/bf02723654.

5. Karunasekera KA, Pathirana D. A preliminary study on neonatal septicaemia in a tertiary referral hospital paediatric unit. The Ceylon Med J. 1999;44(2):81-6. PMID: 10565074.

6. Joshi SG, Ghole VS, Niphadkar KB. Neonatal gram-negative bacteremia. Indian J Pediatr. 2000;67(1):27-32. DOI:10.1007/ bf02802632.

7. Kumhar GD, Ramachandran VG, Gupta P. Bacteriological analysis of blood culture isolates from neonates in a tertiary care hospital in India. J Health Popul Nutr. 2002;20(4):343-7. PMID: 12659415.

8. Chapagain RH, Acharya R, Shrestha N, Giri BR, Bagale BB, Kayastha M. Bacteriological Profile of Neonatal Sepsis in Neonatal Intermediate Care Unit of Central Paediatric Referral Hospital in Nepal. J Nepal Health Res Counc. 2015;13(31):205-8. PMID: 27005713.

9. Softić I. Bacterial sepsis in neonates: Single centre study in a Neonatal intensive care unit in Bosnia and Herzegovina. Acta Medica Academica. 2017;46(1):7-15. DOI:10.5644/ama2006-124.181.

10. Shrestha NJ, Subedi KU, Rai GK. Bacteriological Profile of Neonatal Sepsis: A Hospital Based Study. J Nepal Paedtr Soc. 2011;31(1):1-5. DOI:https://doi.org/10.3126/jnps.v31i1.4158.

11. Jain NK, Jain VM, Maheshwari S. Clinical profile of neonatal sepsis. Kathmandu Univ Med J. 2003;1(2):117-20. PMID: 16388210.

12. Moore KL, Kainer MA, Badrawi N, Afifi S, Wasfy M, Bashir M, et al. Neonatal sepsis in Egypt associated with bacterial contamination of glucose-containing intravenous fluids. Pediatr Infect Dis J. 2005;24(7):590-4. DOI:10.1097/01.inf. 0000168804.09875.95.

13. Motara F BD, Perovic O. Epidemiology of neonatal sepsis at Johannesburg hospital. S Afr J Epidemiol Infect. 2005;20(3):90-3. DOI: $10.1080 / 10158782.2005 .11441243$

14. Thapa B, Thapa A, Aryal DR, Thapa K, Pun A, Khanal S, et al. Neonatal sepsis as a major cause of morbidity in a tertiary center in Kathmandu. J Nepal Med Assoc. 2013;52(192):549-56.

15. Ullah O, Khan A, Ambreen A, Ahmad I, Akhtar T, Gandapor AJ, et al. Antibiotic Sensitivity pattern of Bacterial Isolates of Neonatal Septicemia in Peshawar, Pakistan.Arch Iran Med. 2016;19(12):866-9. DOI: 0161912/AIM.009.

16. T GE, Moges F, Eshetie S, Yeshitela B, Abate E. Bacterial etiologic agents causing neonatal sepsis and associated risk factors in Gondar, Northwest Ethiopia. BMC Pediatr. 2017;17(1):137. DOI: 10.1186/s12887-017-0892-y.

17. Stoll BJ, Hansen N, Fanaroff AA, Wright LL, Carlo WA, Ehrenkranz RA, et al. Changes in pathogens causing early-onset sepsis in very-low-birth-weight infants. N Engl J Med. 2002;347(4):240-7. DOI:10.1056/NEJMoa012657.

18. Akindolire AE, Tongo O, Dada-Adegbola H, Akinyinka O. Etiology of early onset septicemia among neonates at the University College Hospital, Ibadan, Nigeria. J Infect Dev Ctries. 2016;10(12):1338-44. DOI: 10.3855/jidc.7830.

19. Leshem E, Maayan-Metzger A, Rahav G, Dolitzki M, Kuint J, Roytman Y, et al. Transmission of Staphylococcus aureus from mothers to newborns. Pediatr Infect Dis J. 2012;31(4):360-3. DOI: 10.1097/INF.0b013e318244020e.

20. Piush Kanodia SKY, Rupa Rajbhandari Singh, Nisha K Bhatta. Bacteriological Profile of Blood Culture Positive Sepsis in Newborn at BPKIHS, Dharan Nepal. J Col Med Sci. 2017;13(1):4. DOI: https://doi.org/10.3126/jcmsn.v13i1.16663. 